\title{
Paternity displacement in the grasshopper Eyprepocnemis plorans
}

\author{
M. D. LÓPEZ-LEÓN, J. CABRERO, M. C. PARDO, E. VISERAS \& J. P. M. CAMACHO* \\ Departamento de Genética, Facultad de Ciencias, Universidad de Granada, Granada, E-18071, Spain
}

\begin{abstract}
Three types of double crosses were carried out to investigate sperm competition in the grasshopper Eyprepocnemis plorans. Maximum likelihood estimation of paternity probability showed a high degree of second male sperm precedence $\left(P_{2}=90 \%\right)$. The results also showed that: (i) a single copulation may be enough for an efficient paternity displacement; (ii) males do not use sperm plugs, but they mate for a prolonged period of time to resist further copulation; and (iii) successive paternity displacements may be seen in the same female. The mechanisms controlling sperm competition in E. plorans, and the evolutionary implications of this phenomenon are discussed.
\end{abstract}

Keywords: Eyprepocnemis plorans paternity displacement, sexual selection, sperm competition.

\section{Introduction}

Sexual selection, as defined by Darwin $(1871)$ is the consequence of competition between individuals of one sex to reproduce with a member of the other sex. In addition, a gametic level for sexual selection, sperm competition, has been highlighted by Parker (1970).

Sperm competition between males may be enhanced in animals in which the female has sperm storage organs, and multiple mating by females is required for this competition to occur. These two characteristics are widespread among insects (Thornhill \& Alcock, 1983; Smith, 1984; Ridley, 1988). Thus, if the sperm of the first male is still present in the sperm storage organs when the female re-mates, sperm competition occurs. Many insects show last male sperm precedence, the basis of which is to a large extent unknown. The mechanical removal of previous sperm by a specifically adapted penis in some Odonata species is one of the few mechanisms for sperm displacement which has been clearly demonstrated (Waage, 1979; 1984).

In Orthoptera, sperm competition has been analysed in several species, with variable amounts of sperm precedence or mixing. Sperm mixing has been reported in the crickets Gryllodes suplicans (Sakaluk, 1986), G. integer (Backus \& Cade, 1986) and G. bimaculatus (Simmons, 1987), and in the grasshoppers Chorthippus parallelus (Bella et al., 1992) and Podisma pedestris

*Correspondence.
(Hewitt et al., 1989), although in C. parallelus and $P$. pedestris sperm mixing was not at random, but with strong first ( $P$. pedestris) or second $(C$. parallelus) male precedence. The desert locust, Schistocerca gregaria, shows a very high degree of last male sperm precedence (Hunter-Jones, 1960). Finally, the migratory locust Locusta migratoria also shows strong last male sperm precedence, but here part of the spermatophore tube acts as a sperm plug that remains within the spermathecal duct, blocking the passage of the sperm of a second male with an average efficiency of 60 per cent (Parker \& Smith, 1975). When the female lays an egg pod, the plug is ejected so that the next male copulating with the female will transfer his sperm without any impediment, and will block the spermathecal duct with a new plug so that he will be the parent of the progeny in the following egg pod. Therefore, this case can be considered as last male sperm precedence from the inter-egg-pod perspective. Thus, in each podlaying cycle, there is first male sperm precedence on account of the sperm plug, but between successive pod-laying cycles there is last male sperm precedence since paternity displacement is observed. This has led Hewitt et al. (1989) to consider this case as single male fertilization rather than first or last male sperm precedence.

In this paper, we analyse sperm competition between male grasshoppers of the species Eyprepocnemis plorans, by means of double crosses carried out under three different conditions. 


\section{Materials and methods}

We carried out controlled double crosses with specimens of the grasshopper E. plorans caught at Jete and Salobreña (Granada, Spain). Specimens were kept in laboratory cages at $28^{\circ} \mathrm{C}$ and fed daily with fresh grass in addition to wheat bran and some pieces of orange. Several laying tubes containing moist vermiculite were attached to corresponding holes at the bottom of each cage. Three types of cross were performed: (i) type A crosses, where a female was simultaneously placed with two males of unknown karyotypes until the first egg pod was laid; (ii) type B crosses, where a female was first mated with one male and when at least two egg pods had been obtained, the male was replaced by a second one which differed from the former in the cytogenetic markers used (a B chromosome and a supernumerary chromosome segment), until at least two other egg pods were obtained; and (iii) type $\mathrm{C}$ crosses, where a female was simultaneously placed with two males showing differences in the cytogenetic markers, and several egg pods were obtained.

All females used in the crosses were initially virgin since they were collected when they were nymphs and were isolated from males until they reached the adult stage. In crosses with two males simultaneously $(\mathrm{A}$ and $\mathrm{C}$ types), one of the males was marked with nail varnish on the pronotum, and matings were recorded daily. We recorded which male mated with the female. Since copulation lasts about $24 \mathrm{~h}$, an observation in the morning and another in the afternoon were sufficient to record with precision the number of copulations with each male before each egg-pod laying. However, in type A crosses, when a female had mated with both males, the observation of the mating was discontinued, since the objective of these crosses was to test sperm mixing only. In $\mathrm{B}$ and $\mathrm{C}$ crosses, on the other hand, matings were observed and recorded daily until the end of the experiment.

The two males in A crosses were randomly placed with a female, without knowing if they had different cytogenetic markers. However, in B and C crosses males were karyotyped in vivo by extracting some testis follicles through a small incision in the dorsal abdomen, which were fixed and analysed cytologically (see below). Each male that had been operated on was marked with nail varnish of several colours according to a colour code in order to identify it in the cage of operated males, and thus to determine the karyotype of each male for the cytogenetical markers after the cytological analysis of the fixed follicles. Afterwards, each male was used in the crosses as was necessary.

Egg pods were incubated at $28^{\circ} \mathrm{C}$ for 10 days, and then the embryos were dissected from the eggs in insect saline solution with the aid of a stereomicroscope. Embryos were immersed in $1 \mathrm{ml}$ of 0.05 per cent colchicine in insect saline solution and $1 \mathrm{~h}$ later, $1 \mathrm{ml}$ of distilled water was added for hypotonic shock for 15 min prior to their fixation in 1:3 acetic acid:ethanol. Chromosomal preparations of embryos were carried out using the technique described in Camacho et al. (1991). Cytological preparations of the parents were obtained by means of the standard techniques for grasshoppers.

All chromosomal preparations were processed by the C-banding technique described in Camacho et al. (1984), in order to distinguish the cytogenetical markers used for this study. These were B chromosomes and an autosomal supernumerary chromosome segment. While B chromosomes lack any drive, thus showing Mendelian transmission ratio (López-León et al., 1992), the supernumerary segment on $S_{11}$ is partly eliminated by females possessing $\mathrm{B}$ chromosomes through meiotic drive against the segmented $\mathrm{S}_{11}$ chromosomes (López-León et al., 1991). These facts were used to analyse the results of the double crosses in this work.

Since both markers constitute polymorphisms in natural populations, it is very difficult to obtain two males whose offspring from the same female can be distinguished with complete certainty. Thus, if the males differ in the number of $\mathrm{B}$ chromosomes $(0 \mathrm{~B}$ and $2 \mathrm{~B}$, for instance, in the most favourable of cases) the sperm formed by the males are not completely different, since the $2 \mathrm{~B}$ male produces a proportion (although small) of $0 \mathrm{~B}$ sperm. If they differ in the supernumerary chromosome segment, the only case in which the sperm of both males will be securely distinguished is if they are NN and SS (N, non-segmented chromosome; $\mathrm{S}$, segmented chromosome). In any other case ( $\mathrm{NN}$ and NS, or else NS and SS) the sperm of both males are partly similar (50 per cent). For this reason, we employed a statistical algorithm, denoted 'Empat', to estimate the probability of paternity for each male in each cross. Empat is a maximum likelihood paternity estimator (Dempster et al., 1977; Dickinson, 1986; Dickinson \& McCulloch, 1989), which represents the proportion of a brood sired by a given male (Kukuk \& May, 1988; Watson, 1991a; 1991b). We applied it with the aid of a microcomputer program originally devised by McCulloch. To calculate probabilities of paternity in type A and type $\mathrm{C}$ crosses, single paternity was assumed for each male and then progeny karyotype frequencies expected from each male were calculated, bearing in mind the inheritance of the markers (LópezLeón et al., 1991; 1992). However, for paternity analyses in type B crosses, the expected progeny fre- 
quencies for the first male were those observed before substitution with the second male.

\section{Results}

Type A crosses were carried out to ascertain whether females of $E$. plorans do mix the sperm from two different males after having copulated with them, as reflected in the progeny contained in the same egg pod. The results of these five crosses demonstrated absence or very low frequency of sperm mixing (Table 1 ).

Type B crosses were carried out to see whether the absence of sperm mixing shown by type $\mathrm{A}$ crosses corresponded to first or second male sperm precedence. There was a high degree of second male sperm precedence (Table 2), with a mean estimated $\mathrm{P}_{2}$ (the proportion of offspring sired by the second male) equal to $0.902 \pm 0.054$ for the first egg pod and $0.943 \pm 0.038$ for the second egg pod. The relative number of copulations achieved by the second male, with respect to the total number of copulations performed by the female, did not show a significant correlation with $P_{2}$ in the first egg pod after second male mating (Spearman rank correlation $r_{s}=0.292$, d.f. $=8, P=0.414$ ), but both variables showed a high and significant positive correlation in the second egg $\operatorname{pod}\left(r_{\mathrm{s}}=0.701\right.$, d.f. $\left.=8, P=0.024\right)$. Thus, the larger the mating effort performed by the second male relative to that of the first male, the higher the proportion of offspring sired.

We carried out type $C$ crosses to ascertain whether paternity displacement observed in type $\mathrm{B}$ crosses also operates when the female has the opportunity to mate with more than one male, a situation closer to that expected in nature. We analysed 24 egg pods in the five crosses carried out (Table 3). The last male seen copulating with the female before a given egg pod achieved precedence, the only exception being the two first broods in the $\mathrm{C}_{4}$ cross, where an unobserved mating with the marked male ( $\mathrm{mo}^{*}$ ) could have caused the low $P_{2}$ values, and the third brood in $\mathrm{C}_{5}$, where a low $P_{2}$ value was obtained after one mating with each male. Males did not seem to use plugs, since some broods (e.g. pod 3 in $C_{1}$ and pod 4 in $C_{3}$ ), demonstrated complete paternity displacement after one mating with each male. Furthermore, these pods in conjunction with pod 4 in $C_{1}$, pod 3 in $C_{2}$ and pod 2 in $\mathrm{C}_{5}$ demonstrated that a single mating is enough to achieve paternity displacement. The mean $P_{2}$ estimated from the five type $C$ crosses $(0.901)$ did not differ significantly from that obtained in the 10 type $B$ crosses (0.912) (Mann-Whitney test: $U=32, P=0.366$ ).

\section{Discussion}

Our observations suggest that males of E. plorans do not use plugs as a 'resistor' adaptation, similar to that seen in Locusta migratoria (Parker \& Smith, 1975). If they did, the embryos contained in $C_{1}$, pod 3 and $C_{3}$, pod 4 should be progeny from the first male which copulated with the female after the last pod, but not from the last male, as was in fact observed.

Research on sperm precedence in the Acrididae is scanty, but the few cases studied show a variety of situations (see Introduction). Paternity displacement in E. plorans reported here is similar to that observed in Schistocerca gregaria (Hunter-Jones, 1960). This phenomenon is a consequence of male competition depending on mechanisms of sperm precedence, the evolutionary implications of which were first pointed

Table 1 Analysis of sperm mixing in the first egg pod laid by doubly mated females (type A crosses)

\begin{tabular}{|c|c|c|c|c|c|c|}
\hline \multirow[b]{2}{*}{ Cross } & \multicolumn{3}{|c|}{ Parent karyotypes } & \multirow[b]{2}{*}{ Offspring karyotypes } & \multicolumn{2}{|c|}{$\begin{array}{l}\text { Probability } \\
\text { of paternity }\end{array}$} \\
\hline & q & mot & nmơ & & mó & nmot \\
\hline $\mathrm{A}_{1}$ & OBNN & $1 \mathrm{BNS}$ & $1 \mathrm{BNN}$ & $18(0 \mathrm{BNN}): 17(1 \mathrm{BNN})$ & 0 & 1 \\
\hline $\mathrm{A}_{2}$ & $1 \mathrm{BNN}$ & OBNS & 0BNN & $13(0 \mathrm{BNN}): 22(1 \mathrm{BNN})$ & 0 & 1 \\
\hline $\mathrm{A}_{3}$ & 1BNS & $1 \mathrm{BNS}$ & 0BSS & $1(0 \mathrm{BNN}): 1(0 \mathrm{BNS}): 11(1 \mathrm{BNN}): 12(1 \mathrm{BNS}): 2(2 \mathrm{BNN}): 3(2 \mathrm{BNS})$ & 1 & 0 \\
\hline $\mathrm{A}_{4}$ & $1 \mathrm{BNN}$ & $2 \mathrm{BNN}$ & 2BSS & 3 (0BNS): $29(1 \mathrm{BNS}): 12(2 \mathrm{BNS}): 2(3 \mathrm{BNS})$ & 0 & 1 \\
\hline $\mathrm{A}_{5}$ & 2BNN & $2 \mathrm{BNN}$ & 2BNS & $\begin{array}{l}7(1 \mathrm{BNN}): 6(1 \mathrm{BNS}): 13(2 \mathrm{BNN}): 14(2 \mathrm{BNS}): 2(3 \mathrm{BNN}): 3(3 \mathrm{BNS}): \\
1(4 \mathrm{BNN})\end{array}$ & 0 & 1 \\
\hline
\end{tabular}

Karyotypes refer to two markers: a B chromosome (0B, 1B, 2B, 3B, 4B) and a supernumerary chromosome segment (NN, NS, $\mathrm{SS}$, where $\mathrm{N}=$ non-segmented chromosome and $\mathrm{S}=$ segmented chromosome).

mơ, marked male; nmơ, non-marked male. 


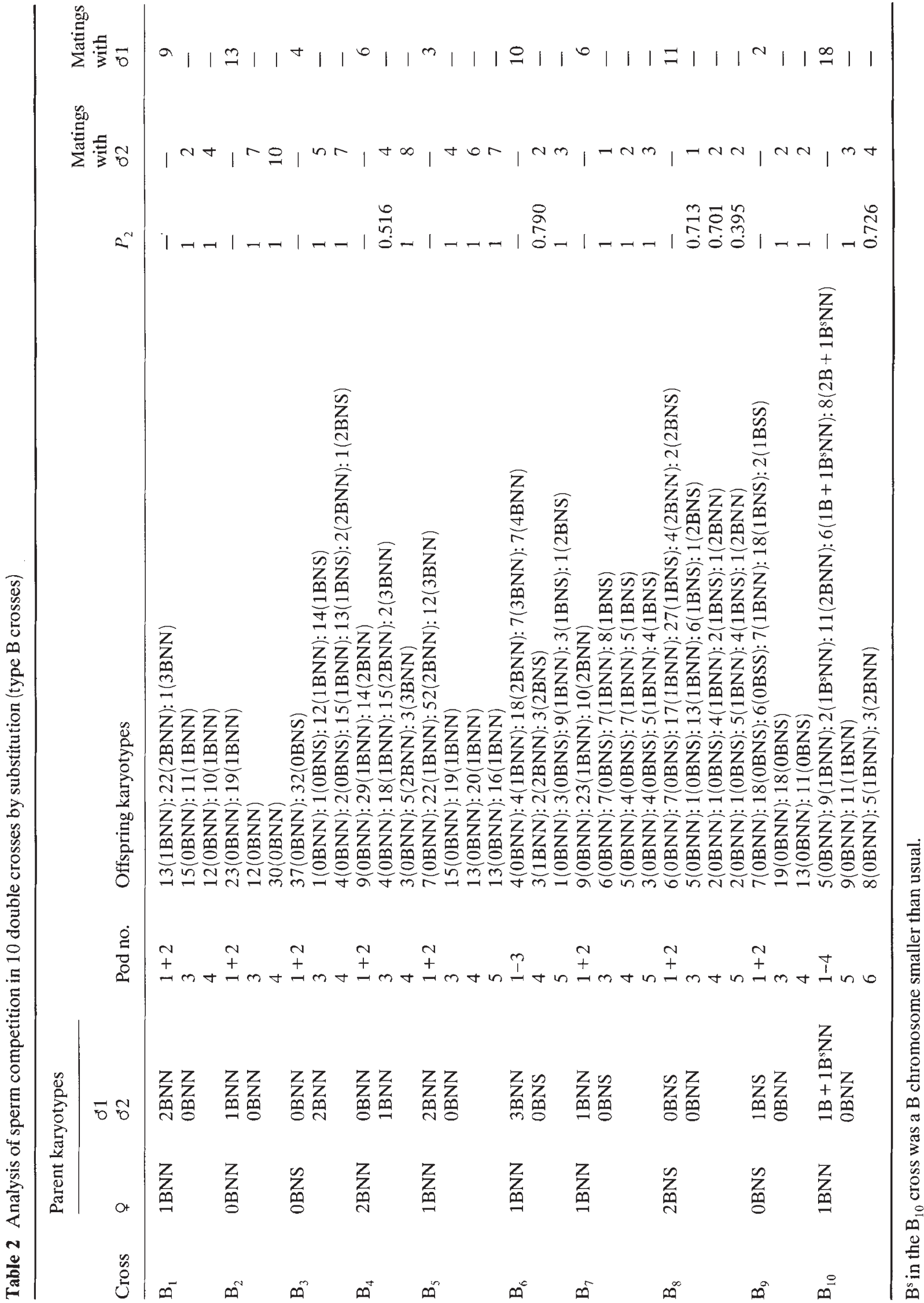




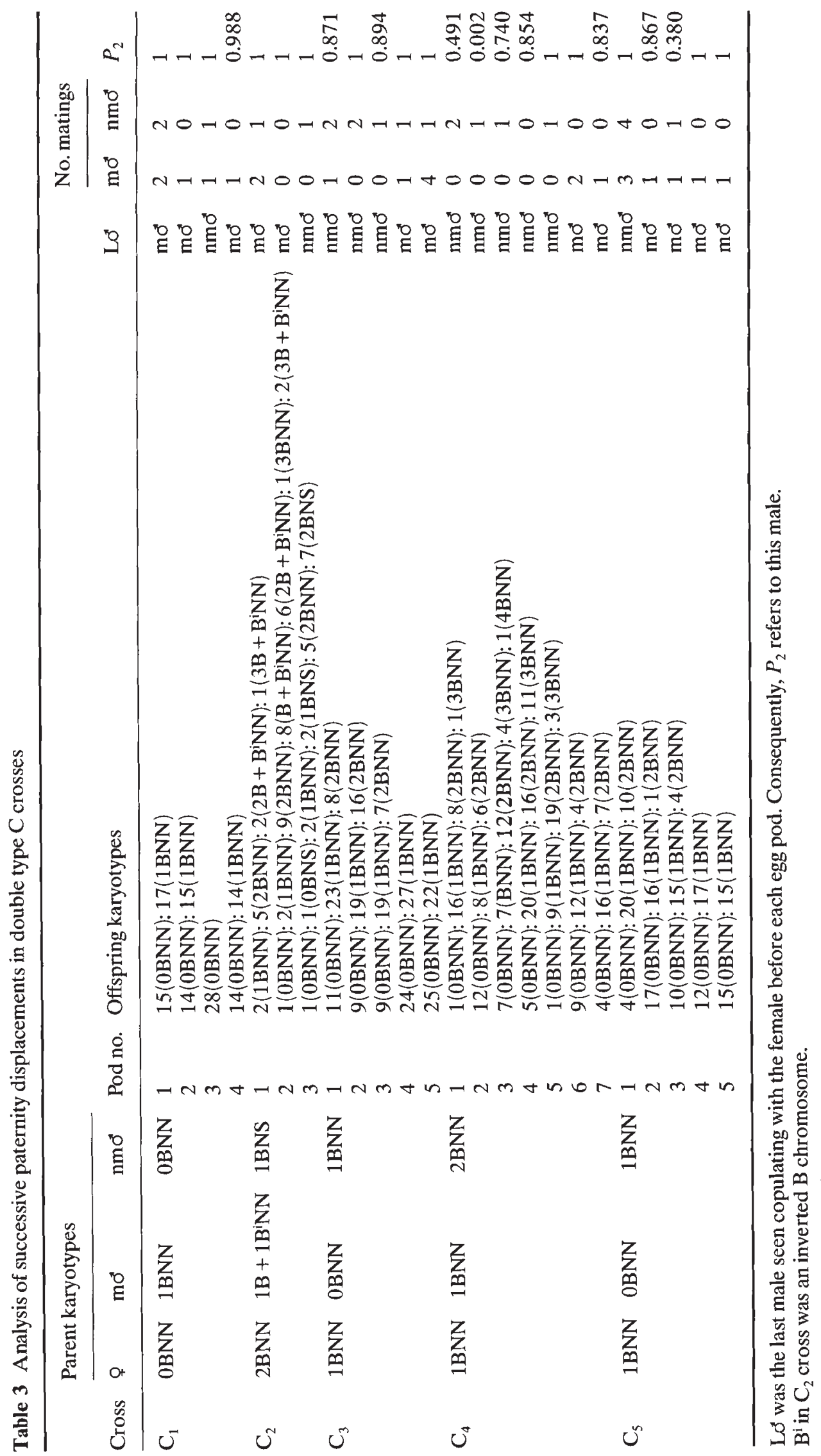


out by Parker (1970). All these mechanisms are focused to secure paternity and include a variety of adaptations, some of which may be considered as 'first male' adaptations and others as 'second male' adaptations. These produce, respectively, two opposite male strategies, 'resistor' and 're-mater' (Gromko et al., 1984). In E. plorans, male strategies seem to be predominantly of the 're-mater' type, since paternity displacement should favour those males with a high copulating activity. This is supported by the positive correlation between $P_{2}$ and the relative mating frequency of the second male in type $\mathrm{B}$ crosses. However, at least one feature which could be considered as a 'resistor' adaptation is observed in $E$. plorans males, namely the prolonged copulation $(24 \mathrm{~h}$ on average), which may be a type of female guarding with the male acting as a mechanical plug (Parker, 1970). The female strategy is multiple mating, at least in the laboratory. Females of E. plorans mate, on average, four or five times before laying the first egg pod, and once in each subsequent pod cycle. Multiple mating is only slightly justified by sperm replenishment, since median sperm survival in E. plorans females is equal to about 2 months and only a minority of females show signs of sperm depletion after a single copulation (López-León, M. D. et al., unpub. obs.).

We have recently observed the existence of nutrient transfer with the ejaculate and a parallel increase in the rate of egg and embryo production, both of which are positively correlated with mating frequency (Pardo, M. C. et al., unpub. obs.). This could be the main benefit obtained by females from multiple mating. Nutrient transfer has been demonstrated in several insects, mainly in Lepidoptera and Orthoptera (Gwynne, 1984). In grasshoppers, male nutrient transfer has been shown in Melanoplus sanguinipes (Friedel \& Gillott, 1977) and Chorthippus brunneus, where it is followed by increases in female fecundity (Butlin et al., 1987). Walker (1980) claims that in species where males provide benefits to females, a high level of last male sperm precedence should occur since it would be a reward for males. This assumption seems to be supported by the scarce cases where sperm competition and male parental investment and mating effort have been studied, mainly in Lepidoptera (see Gwynne, 1984). The only grasshopper species with both features known is E. plorans, and the results are consistent with Walker's hypothesis.

The mechanisms controlling paternity displacement may be classified as active and passive (Drummond, 1984). Active mechanisms may be determined by the female; for example, muscular control of sperm movement and storage within the female reproductive tract, or inactivation of stored sperm by means of hormonal influences or nutritional deprivation. On the other hand, active mechanisms may be determined by the male; for instance, physical displacement of sperm stored from a previous mating (Waage, 1979) or incapacitation of previous sperm. Passive factors may be the basic genital anatomy of the female or the sperm storage capacity of the female, which depends on the size and shape of the spermatheca.

Walker (1980) has noted that insect species with strong last male sperm precedence have elongated or ovoid spermathecae. This is true for E. plorans, which has an ovoid spermatheca joined through a single duct to the vagina, so that sperm must pass through this duct on their way into the storage organ, and then return by the same route to fertilize eggs. This coincides with the cul-de-sac spermatheca described in spiders by Austad (1984). Thus, with these anatomical features in mind, it is logical that the last sperm entering the spermatheca must be the first going out to fertilize eggs. This may be the basis of paternity displacement in E. plorans, but the sperm of different males must not by necessity mix in the spermatheca.

\section{Acknowledgements}

We are grateful to Prof. G. M. Hewitt and two anonymous referees for comments on the manuscript. We are also indebted to Dr P. J. Watson for providing the 'Empat' program. This study was partially supported by grants from the Dirección General de Investigación Científica y Técnica (no. PB90-0865) and the Plan Andaluz de Investigación, Grupo no. 3122 (Spain).

\section{References}

AUSTAD, S. N. 1984. Evolution of sperm priority patterns in spiders. In: Smith, R. L. (ed.), Sperm Competition and the Evolution of Animal Mating Systems, Academic Press, New York, pp. 223-249.

BACKUS, V. L. AND CADE, w. H. 1986. Sperm competition in the field cricket Gryllus integer. Fla. Entomol., 69, 722-728.

BELlA, J. L., BuTlin, R. K., FERRIS, C. AND HEWITT, G. M. 1992. Asymmetrical homogamy and unequal sex ratio from reciprocal mating-order crosses between Chorthippus parallelus subspecies. Heredity, 68, 345-352.

BUTLIN, R. K., WOODHATCH, C. W. AND HEWITT, G. M. 1987. Male spermatophore investment increases female fecundity in a grasshopper. Evolution, 41, 221-225.

CAMACHO, J. P. M., viSERAS, E., NAVAS, J. AND CABRERO, J. 1984. C-heterochromatin content of supernumerary chromosome segments of grasshoppers: detection of an euchromatic extra segment. Heredity, 53, 167-175. 
CAMACHO, J. P. M., CABRERO, J., VISERAS, E., LÓPEZ-LEÓN, M. D., NAVAS-CASTILLO, J. AND ALCHE, J. D. 1991. G banding in two species of grasshopper and its relationship to $\mathrm{C}, \mathrm{N}$ and fluorescence banding techniques. Genome, 34, 638-643.

DARWIN, C. 1871. The Descent of Man, and Selection in Relation to Sex. Appelton, New York.

DEMPSTER, A. P., LAIRD, N. P. AND RUBIN, D. B. 1977. Maximum likelihood from incomplete data via the EM Algorithm. Proc. Roy. Soc. B, 39, 1-38.

DICKINson, J. L. 1986. Prolonged mating in the milkweed leaf beetle Labidomera clivicollis clivicollis (Coleoptera: Chrysomelidae): a test of the 'sperm-loading' hypothesis. Behav. Ecol. Sociobiol., 18, 331-338.

DICKINSON, J. L. AND McCULLOCH, C. E. 1989. Use of maximum likelihood estimation to apportion broods among potential sires. Anim. Behav., 38, 719-721.

DRUMMOND, B. A. 1984. Multiple mating and sperm competition in the Lepidoptera. In: Smith, R. L. (ed.), Sperm Competition and the Evolution of Animal Mating Systems, Academic Press, New York, pp. 291-370.

FRIEDEL, T. AND GILLOTT, C. 1977. Contribution of maleproduced proteins to vitellogenesis in Melanoplus sanguinipes. J. Insect Physiol., 23, 145-151.

GROMKO, M. H., GILBERT, D. G. AND RICHMOND, R. C. 1984. Sperm transfer and use in the multiple mating system of Drosophila. In: Smith, R. L. (ed.), Sperm Competition and the Evolution of Animal Mating Systems, Academic Press, New York, pp. 371-426.

GWYNNE, D. T. 1984. Male mating effort, confidence of paternity, and insect sperm competition. In: Smith, R. L. (ed.), Sperm Competition and the Evolution of Animal Mating Systems, Academic Press, New York, pp. 117-149.

HEWITT, G. M., MASON, P. AND NICHOLS, R. A. 1989. Sperm precedence and homogamy across a hybrid zone in the alpine grasshopper Podisma pedestris. Heredity, 62, 343-353.

HUNTER-JONES, P. 1960. Fertilization of eggs of the desert locust by spermatozoa from successive copulations. Nature, 185, 336.

KUKUK, P. F. AND MAY, B. P. 1988. Dominance hierarchy in the primitively eusocial bee Lasioglossum (Dialictus) zephyrum: is genealogical relationship important? Anim. Behav., 36, 1848-1850.
LÓPEZ-LEÓN, M. D., CABRERo, J. AND CAMACHo, J. P. M. 1991. Meiotic drive against an autosomal supernumerary segment promoted by the presence of a B chromosome in females of the grasshopper Eyprepocnemis plorans. Chromosoma, 100, 282-287.

LÓPEZ-LEÓN, M. D., CABRERO, J., CAMACHO, J. P. M., CANO, M. I. AND SANTOS, J. L. 1992. A widespread B chromosome polymorphism maintained without apparent drive. Evolution, 46, 529-539.

PARKER, G. A. 1970. Sperm competition and its evolutionary consequences in the insects. Biol. Rev., 45, 525-567.

PARKER, G. A. AND SMITH, J. L. 1975. Sperm competition and the evolution of the precopulatory passive phase behaviour in Locusta migratoria migratorioides. J. Entomol., 49, 155-171.

RIDLEY, M. 1988. Mating frequency and fecundity in insects. Biol. Rev., 63, 509-549.

SAKALUK, S. K. 1986. Sperm competition and the evolution of nuptial feeding behavior in the cricket, Gryllodes supplicans (Walker). Evolution, 40, 584-593.

SIMMONS, L. w. 1987. Sperm competition as a mechanism of female choice in the field cricket, Gryllus bimaculatus. Behav. Ecol. Sociobiol., 21, 197-202.

SMITH, R. L. (ed.). 1984. Sperm Competition and the Evolution of Animal Mating Systems, Academic Press, New York.

THORNHILL, R. AND ALCOCK, J. 1983. The Evolution of Insect Mating Systems, Harvard University Press, Cambridge.

WAAGE, J. K. 1979. Dual function of the damsel fly penis: Sperm removal and transfer. Science, 203, 916-918.

WAAGE, J. K. 1984. Sperm competition and the evolution of Odonate mating systems. In: Smith, R. L. (ed.), Sperm Competition and the Evolution of Animal Mating Systems, Academic Press, New York, pp. 251-290.

WALKER, W. F. 1980. Sperm utilization strategies in nonsocial insects. Am. Nat., 115, 780-799.

WATSON, P. J. 1991a. Multiple paternity and first mate sperm precedence in the sierra dome spider, Linyphia litigiosa. Anim. Behav., 41, 135-148.

WATSON, P. J. 1991 b. Multiple paternity as genetic bet-hedging in female sierra dome spiders, Linyphia litigiosa (Linyphiidae). Anim. Behav., 41, 343-360. 